OPEN ACCESS

Edited by:

Uma Tiwari,

Technological University

Dublin, Ireland

Reviewed by:

George Lazaroiu,

Spiru Haret University, Romania

Qiuying Zhang,

Northeast Institute of Geography and Agroecology, Chinese Academy of

Science (CAS), China

*Correspondence:

Susan E. Duncan

duncans@vt.edu

${ }^{\dagger}$ Present addresses:

Renata C. V. Carneiro,

Department of Chemistry and Fermentation Sciences, Appalachian

State University, Boone, NC,

United States

Clinton L. Neill,

Dyson School of Applied Economics and Management, Cornell University,

Ithaca, NY, United States

Specialty section:

This article was submitted to

Nutrition and Sustainable Diets,

a section of the journal

Frontiers in Sustainable Food Systems

Received: 04 July 2021

Accepted: 27 December 2021

Published: 18 January 2022

Citation:

Carneiro RCV, Drape TA, Neill CL,

Zhang B, O'Keefe SF and Duncan SE

(2022) Assessing Consumer

Preferences and Intentions to Buy

Edamame Produced in the U.S..

Front. Sustain. Food Syst. 5:736247.

doi: 10.3389/fsufs.2021.736247

\section{Assessing Consumer Preferences and Intentions to Buy Edamame Produced in the U.S.}

\author{
Renata C. V. Carneiro ${ }^{1 \dagger}$, Tiffany A. Drape ${ }^{2}$, Clinton L. Neill ${ }^{3 \dagger}$, Bo Zhang $^{4}$, Sean F. O'Keefe ${ }^{1}$ \\ and Susan E. Duncan ${ }^{1 *}$ \\ 'Department of Food Science and Technology, Virginia Tech, Blacksburg, VA, United States, ${ }^{2}$ Department of Agricultural, \\ Leadership, and Community Education, Virginia Tech, Blacksburg, VA, United States, ${ }^{3}$ Department of Agricultural and \\ Applied Economics, Virginia Tech, Blacksburg, VA, United States, ${ }^{4}$ School of Plant and Environmental Sciences, Virginia \\ Tech, Blacksburg, VA, United States
}

Due to the growing consumer demand for edamame (vegetable soybean) in the U.S., the domestic production of this specialty crop has been promoted in several MidAtlantic and Southeast states as an economically attractive alternative to replace the decreasing tobacco production. For the edamame agrobusiness to be successful in the U.S., consumer studies are as needed as new commercial cultivars that are developed for the U.S. environment. Thus, in this exploratory study, we investigated consumers' preferences and intentions to buy edamame products in the U.S., especially domestic products. Data was collected through a web-based survey distributed through Qualtrics $\mathrm{XM}$ and a convenience sampling method was chosen. Volunteers who completed the survey $(N=309)$ were $82 \%$ female, $57 \%$ residents of the South Atlantic area, and $79 \%$ daily consumers of vegetables. Survey respondents had a positive attitude toward domestically produced vegetables and valued supporting U.S. producers. Overall, domestically grown, in-shell edamame products were preferred compared to shelled edamame or imported products. Regarding future purchasing, respondents exhibited higher intention to buy fresh edamame relative to frozen edamame. Additionally, respondents considered price, availability, and familiarity with the vegetable brand, respectively, as the most important factors in their decision-making process to buy edamame products. Our study confirmed there is a market potential for domestically produced edamame and it also provides valuable information to support future studies, production decisions, and the growth of the edamame agrobusiness in the U.S.

Keywords: Glycine $\max (\mathrm{L}$.$) Merr., vegetable soybean, specialty crop, domestic production, survey$

\section{INTRODUCTION}

Edamame is the Japanese name for vegetable soybean (Glycine max (L.) Merr.), a nutritious vegetable crop widely consumed in Asian countries, mostly as a snack (Mebrahtu and Devine, 2008; Carneiro et al., 2020). In the past two decades, edamame sales and consumption have been increasing in the U.S. (Zhang and Kyei-Boahen, 2007; Wolfe et al., 2018; Neill and Morgan, 2021), which has aroused the interest of breeders, growers, and food processors to produce this specialty crop in the country (Ogles et al., 2016). In the Mid-Atlantic and Southeast areas of the U.S., for 
example, edamame has been suggested as a promising alternative crop to substitute traditional row crops, such as tobacco (Carson et al., 2011; Neill and Morgan, 2021). Additionally, edamame can be an important ally to increase average consumption of fruit and vegetables in the U.S., which remains lower than recommended by the Dietary Guidelines for Americans (Storey and Anderson, 2018). Nevertheless, several challenges still need to be addressed to reduce the increasing need for imports and promote domestic production of edamame in the U.S. For instance, the development of improved seeds and machinery that reduces the exhaustive nature of labor during production and harvest of edamame, improvements in weed management, the absence of processing facilities, and restricted consumer base and firmly established marketing channels are some major challenges that have been identified in the literature (Zhang and Kyei-Boahen, 2007; Zhang et al., 2017). Although the U.S. is one of the largest soybean producers in the world, most domestic soybeans are targeted to animal feed and food ingredients. Seasonal production and short harvest period also hamper the supply of fresh edamame in the country and increase the demand for imports. As a result, most edamame beans and pods sold in the U.S. are in their frozen form and there is very limited availability of fresh edamame for the domestic market (Montri et al., 2006; Nolen et al., 2016; Wolfe et al., 2018).

Only a few studies have gathered information about preferences, motivations, and purchase intentions of edamame consumers in the U.S. market (Carneiro et al., 2020), which results in a lack of recent information regarding which factors may drive edamame consumption and sales in the country. Relevant studies on consumption and purchase intention of edamame were performed in the metropolitan Philadelphia area, PA in the early 2000s (Kelley and Sánchez, 2005; Montri et al., 2006). However, consumer profile and food trends have significantly changed in the last two decades, which motivated our research group to perform this exploratory consumer study. Recent data can help construct a more accurate picture of current and potential edamame consumers and this information can be used, for example, to support the development of a sustainable edamame agrobusiness in the U.S. Understanding current needs and preferences of domestic vegetable consumers, as well as their motivational factors to introduce, include, and sustain edamame in their shopping and diet (retail, food service, and in-home) is vital to prepare key messages to farmers, processors, health specialists, and consumers at all stages of the agriculture and food systems, including the development of new edamame cultivars through plant-breeding efforts and production decisions (Nardi et al., 2019; Carneiro et al., 2020). In this study, we hypothesized consumers in the U.S. have a positive attitude toward domestically produced edamame and investigated consumers' intention to purchase different types of edamame products. Our goal was to identify consumer preferences that could support business decisions, future research, and potentially promote the domestic production and consumption of edamame.
TABLE 1 | Theories, models, and disciplines for food consumer science.

\begin{tabular}{ll}
\hline Theory or model & Discipline/knowledge field \\
\hline $\begin{array}{l}\text { Asymmetry of information } \\
\text { Economic household models }\end{array}$ & Economics \\
Economy of quality & \\
Food safety economics & \\
Institutional economics & Food science/nutrition \\
Bio-psychological approach & \\
Health belief model & Psychology \\
Theory of reasoned action (TRA) & \\
Theory of planned behavior (TPB) & Sociology \\
Food choice & \\
Process model & Communication \\
Theory of linear knowledge transfer or & \\
demand driven & Marketing \\
Food supply chain management & \\
\hline
\end{tabular}

Adapted from Barjolle et al. (2013).

\section{MATERIALS AND METHODS}

\section{Survey}

Several theories and models have been used as framework to guide food consumer studies (Table 1). In this exploratory study, the constructs of the Theory of Planned Behavior (TPB) (Ajzen, 1991), attitudes, subjective norms, and perceived behavior control, were the basis of the questionnaire designed to investigate preferences and intention of consumers in the U.S. to buy and consume edamame products, especially domestically produced products. The TPB states that it is possible to predict the intention one has to perform different behaviors (e.g., food consumption behavior) by considering an individual's attitudes toward behavior (e.g., individual's beliefs about consequences of consuming a specific food product), subjective norms (e.g., beliefs about other people's approval or disapproval to a specific food consumption-social pressure), and perceived behavioral control (e.g., factors that individuals believe would make it easier or harder to consume a specific food). Also, according to Ajzen (1991), a behavior is more likely to be performed when there is a strong intention to perform it (Figure 1).

Our survey contained an initial consent-in survey question (question 0), which was followed by 33 exploratory questions. Survey questions were mostly adapted from Vabø and Hansen (2016) and grouped as follows: current food (vegetable/edamame) consumption behavior (1-2), attitudes (3-15), subjective norms (16-21), perceived behavioral control (22-28), purchase intentions (29), and demographics (30-33). Participants were asked to answer most questions (3-24 and 26-28) using a 6-point Likert scale ( 1 = "strongly disagree"; $6=$ "strongly agree"; no neutral point). Questions 1-2, 30-31, and 33 were closed-ended multiple-choice questions, 25 and 29 were ranking questions, and question 32 was an open-ended question. 


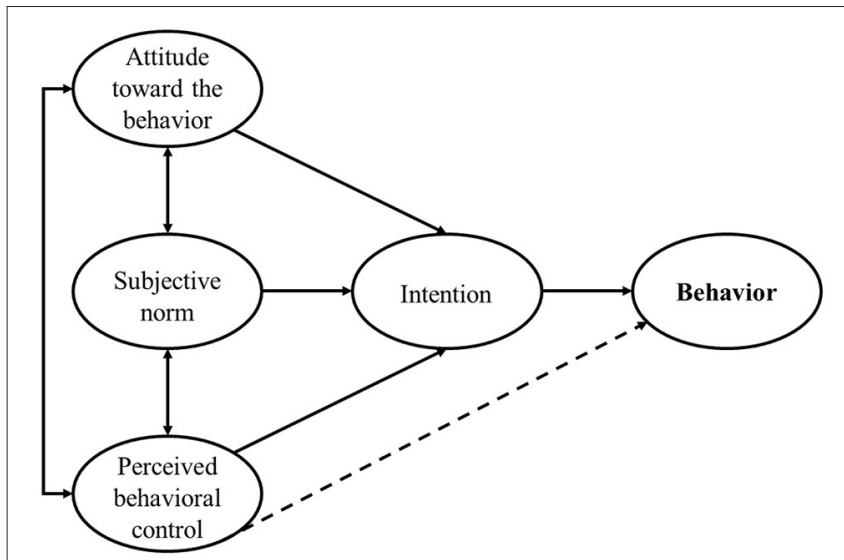

FIGURE 1 | Theory of planned behavior (TPB). Adapted from Ajzen (1991).

\section{Sample}

The non-probability convenience sampling method was chosen and participation was based on the volunteer's willingness to take part in the study. Before beginning our investigation, this study obtained ethical approval from the Virginia Tech Institutional Review Board (IRB) for research involving human subjects (IRB 20-023). Then, data collection was open for 7.5 weeks through Qualtrics ${ }^{\mathrm{XM}}$ (Qualtrics, Provo, UT), a webbased survey platform. Recruitment of participants occurred through direct posts in the Virginia Tech Daily News and social media, listservs, and direct emails that contained the survey link or QR code; no compensation was provided. A total of 415 volunteers ( $\geq 18$ years old) gave informed consent before taking part on this study, which occurred online by answering "I agree to participate" in the initial consent-in survey question. However, only 314 participants (75.7\%) filled out the whole survey. Although the consent question stated the survey was directed to adults living in the U.S. at the time the survey was taken, 5 volunteers answered on question 32 ("In which state of the United States do you currently live?") they were not living in the U.S. and their results were not considered for statistical analysis. Therefore, a total of 309 complete surveys answered by U.S. residents were considered for statistical analysis.

\section{Data Analysis}

The frequencies of participants for demographic questions and behavioral questions were calculated and chi-square test of independence was performed to investigate relationship between two categorical variables (for example, vegetable or edamame consumption and gender). Cronbach's alpha was used to evaluate internal consistency of the TPB questions (attitude, subjective norms, perceived behavioral control). Spearman's rank-order correlation tests were performed to determine the relationship between consumers' choices in questions 25 and 29. A 5\% significance level $(\alpha=0.05)$ was considered for statistical analysis, which was performed using JMP ${ }^{\circledR}$ Pro 15.0.0.

\section{RESULTS AND DISCUSSION}

\section{Consumer's Self-Identity and Vegetable/Edamame Consumption}

The demographic profile (self-identity) of the participants who completed the questionnaire and answered they were living in the U.S. at the time the survey was taken $(n=309)$ is shown in Table 2. Most volunteers were self-identified as female (82\%), between 21 and 29 years old (36\%), residents of the South Atlantic area $(57 \%)$, and their household income was $<\$ 100,000(64 \%$; $<\$ 50,000=32 \%)$. On average, our participants were more likely to consume vegetables one or more times per day (79\%) and consume edamame a few times per year (52\%) as part of their diet. A very similar consumption behavior was reported by the participants of our sensory studies performed over 2 consecutive years in Blacksburg, VA (Carneiro et al., 2021); considering the average of both years, our sensory participants, who were mostly female (55\%), reported their intentional vegetable consumption was at least once a day (69\%) and consumption of edamame was a few times per year (49\%). Even though the demand for edamame in the U.S. has been increasing $12-15 \%$ annually (Neill and Morgan, 2021), our studies confirmed the frequency in which consumers include edamame in their diets is still low and it suggests the edamame market has potential to continue growing in the country.

The relationship (dependence) between edamame consumption or vegetable consumption, and gender identity, age range, total household income, or U.S. region were tested. Chi-square test only suggested a positive relationship between edamame consumption and gender identity $(p<0.05)$, as well as between vegetable consumption and gender identity $(p<0.05)$. However, our dataset was skewed toward female respondents, which was likely due to the limitations of the convenience sampling method chosen for this study. Previous consumer studies on fruit and vegetable consumption (Emanuel et al., 2012) and on edamame (Kelley and Sánchez, 2005; Montri et al., 2006) that were conducted in the U.S. also showed female volunteers were more likely to participate in the studies. Nevertheless, we suggest that the relationships between gender identity and vegetable or edamame consumption that were reported above should be reviewed with a more balanced dataset. Cultural factors are also recognized as dominant factors in food choice (Steptoe et al., 1995; Pocol et al., 2021) and a previous consumer study on edamame considered reported ethnicity for data analysis, due to the fact edamame is traditionally consumed in Asian countries (Kelley and Sánchez, 2005). In this study, ethnic/racial background of participants was not investigated and it is noted as a potential limitation of the work. Additionally, it is known that consumers consider other food-related associations beyond exclusively satisfying their nutritional needs; lifestyle, healthiness, convenience, and sensory appeal are just some examples of other factors that can be considered when making dietary choices (Barjolle et al., 2013). Our study did not identify psychological or individual traits in consumers, such as lifestyle and healthiness. Thus, we suggest that further studies investigate whether consumers identify themselves as vegetarians or vegans, have concerns regarding their health, or follow a particular 
TABLE 2 | Demographic profile of participants.

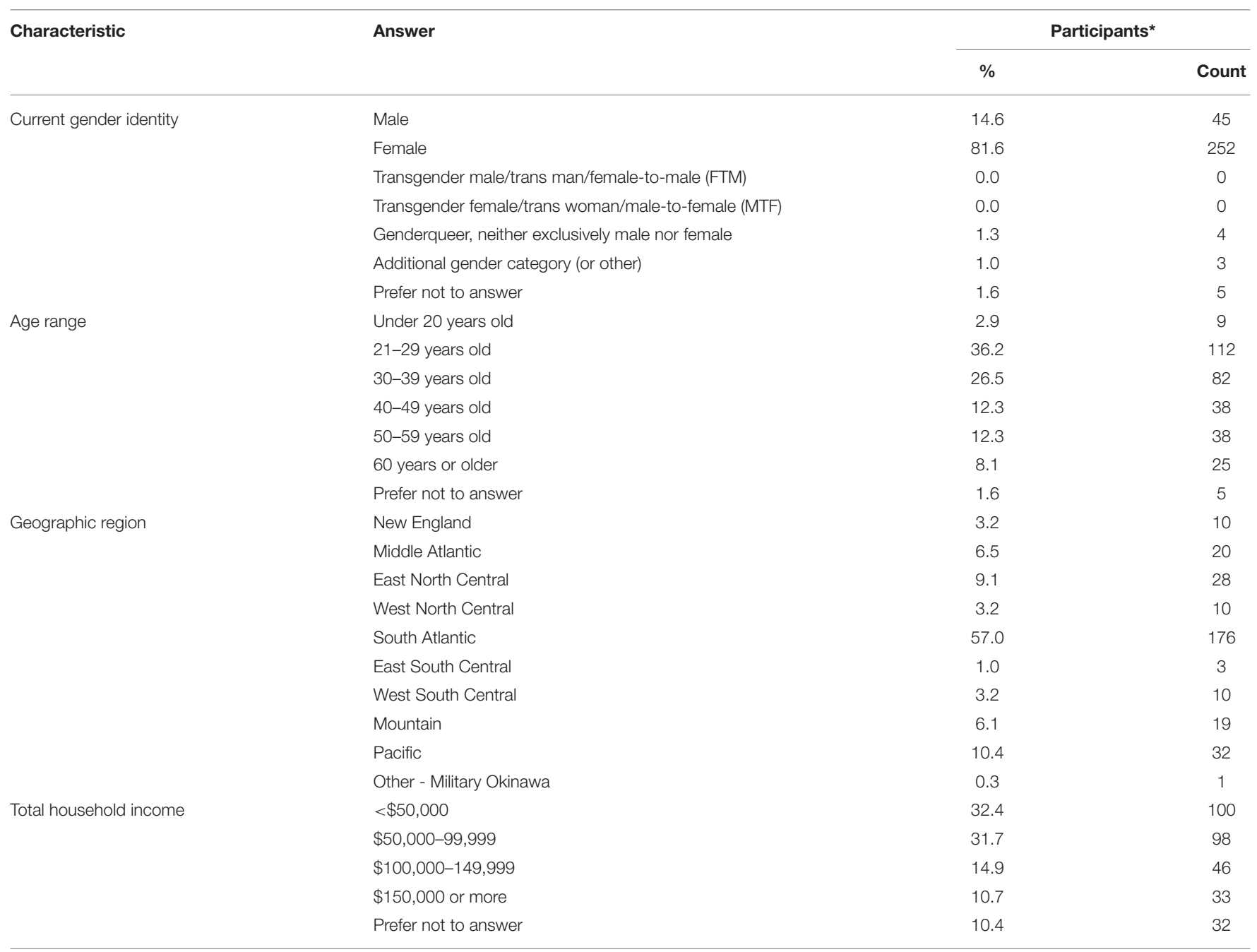

*Only completed surveys answered by consumers living in the U.S. at the time the survey was taken were considered ( $n=309)$.

diet. Another limitation that we identified is self-reporting bias. Even though the reliance on self-reported behavior measures is common in this type of consumer studies, it can be seen as a limitation (Carfora et al., 2015).

\section{TPB Constructs: Attitude, Subjective Norms, and Perceived Behavioral Control}

Descriptive statistics (means and standard deviations) for TPB constructs (attitude, subjective norms, and perceived behavioral control) are shown in Table 3. Cronbach's alpha scores showed "questionable" internal consistency for attitudes (0.68), "acceptable" internal consistency for subjective norms (0.79), and "poor" internal consistency for perceived behavioral control (0.58) (Gliem and Gliem, 2003). Results shown in Table 3 suggest consumers in the U.S. have a positive impression of domestic vegetables (produced in the U.S.) (mean $=4.8 \pm 1.1$; Likert scale: $4=$ "Somewhat agree" and $5=$ "Agree"), as hypothesized. Our survey respondents also had a positive impression of the vegetable seller when choosing edamame (mean $=4.3 \pm$
0.9). Regarding their attitude toward edamame products, they strongly agreed that it is important to them that edamame is safe for consumption, which means the product does not offer risk of food poisoning or foodborne illness (mean $=5.7 \pm$ 0.6; Likert scale: $6=$ "Strongly agree"). A somewhat neutral opinion was observed when participants were asked whether domestically produced edamame is safer for consumption than imported edamame $($ mean $=3.5 \pm 1.2$; Likert scale: $3=$ "Somewhat disagree" and 4 = "Somewhat agree"). Nevertheless, participants showed highest agreement with the subjective norms that by choosing domestically produced edamame they support domestic producers (mean $=5.1 \pm 0.9$ ) and supporting domestic edamame producers is important to them (mean $=4.3 \pm 1.1$ ). These results are of great importance because they suggest consumer acceptability of domestic edamame in the U.S. market and justify breeding efforts to develop improved seeds to be grown in the country. However, it is relevant to remember that other factors can also drive edamame acceptability in the U.S., such as sensory characteristics (Carneiro et al., 2021). Recently, 
TABLE 3 | Mean likeness and standard deviation of theory of panned behavior (TPB) variables.

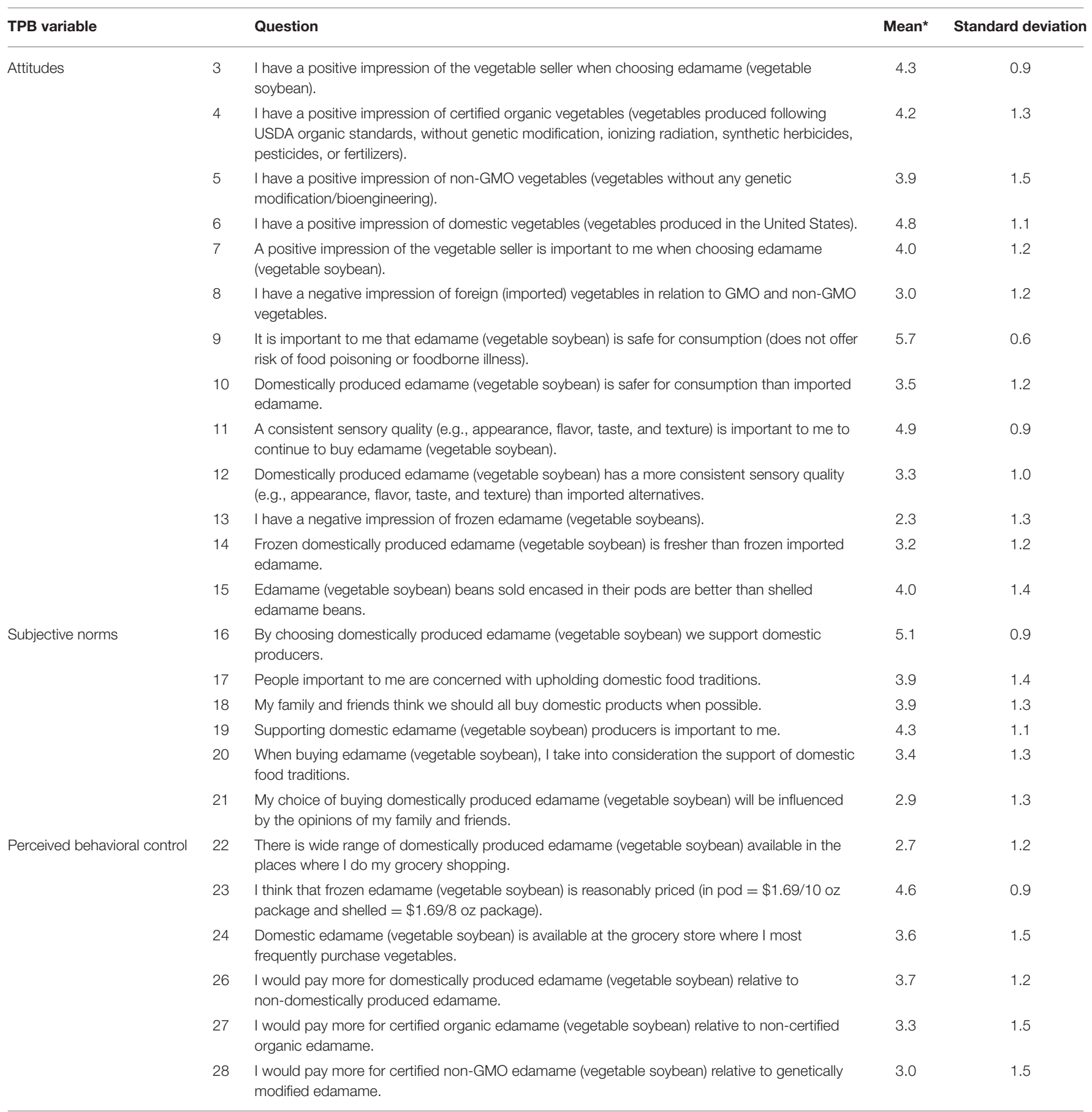

"6-point Likert scale (1 = "strongly disagree"; 3 = "slightly disagree"; 4 = "Slightly agree"; 6 = "strongly agree"; no neutral point). Only completed surveys answered by consumers living in the U.S. at the time the survey was taken were considered $(n=309)$.

Flores et al. (2019) reported that higher scores in overall liking, texture and appearance of different edamame cultivars increased the odds of consumers answering "yes" in their question about purchase intention. In this study, respondents agreed that a consistent sensory quality (e.g., appearance, flavor, taste, and texture) is important to them to continue to buy edamame (mean
$=4.9 \pm 0.9$ ), but slightly disagreed that domestically produced edamame has a more consistent sensory quality than imported alternatives (mean $=3.3 \pm 1.0$ ). These results reinforce the importance of applying sensory evaluation methods to guide edamame development, which was discussed in previous review article (Carneiro et al., 2020) and is currently being done by 
TABLE 4 | Important factors and product characteristics considered by consumers during decision process to buy edamame.

\begin{tabular}{|c|c|c|c|c|c|c|c|c|c|c|}
\hline \multirow[t]{3}{*}{ Factor or product characteristic } & \multicolumn{8}{|c|}{ Importance in purchase decision process - rank* } & \multirow[t]{3}{*}{ Total count } & \multirow[t]{3}{*}{ Factor rank } \\
\hline & \multicolumn{2}{|c|}{1} & \multicolumn{2}{|c|}{2} & \multicolumn{2}{|c|}{3} & \multicolumn{2}{|c|}{4} & & \\
\hline & $\%$ & Count & $\%$ & Count & $\%$ & Count & $\%$ & Count & & \\
\hline Price & 39.1 & 106 & 30.6 & 83 & 14.4 & 39 & 15.9 & 43 & 271 & 1 \\
\hline Availability & 38.3 & 95 & 27.8 & 69 & 19.8 & 49 & 14.1 & 35 & 248 & 2 \\
\hline Familiarity with the vegetable brand & 7.6 & 11 & 20.7 & 30 & 38.6 & 56 & 33.1 & 48 & 145 & 3 \\
\hline Frozen edamame in the pods & 16.2 & 19 & 21.4 & 25 & 29.9 & 35 & 32.5 & 38 & 117 & 4 \\
\hline Domestically produced (not imported) & 11.6 & 13 & 22.3 & 25 & 21.4 & 24 & 44.6 & 50 & 112 & 5 \\
\hline Fresh (not frozen) edamame pods & 21.8 & 22 & 29.7 & 30 & 26.7 & 27 & 21.8 & 22 & 101 & 6 \\
\hline Certified organic & 18.5 & 17 & 16.3 & 15 & 34.8 & 32 & 30.4 & 28 & 92 & 7 \\
\hline Frozen shelled edamame beans (not in pods) & 13.3 & 8 & 20.0 & 12 & 36.7 & 22 & 30.0 & 18 & 60 & 8 \\
\hline Non-GMO & 21.4 & 12 & 28.6 & 16 & 25.0 & 14 & 25.0 & 14 & 56 & 9 \\
\hline Fresh (not frozen) shelled edamame beans & 15.6 & 5 & 12.5 & 4 & 34.4 & 11 & 37.5 & 12 & 32 & 10 \\
\hline Imported only & 50.0 & 1 & 0.0 & 0 & 0.0 & 0 & 50.0 & 1 & 2 & 11 \\
\hline
\end{tabular}

${ }^{*} 1=$ The most important factor or product characteristic. Only completed surveys answered by consumers living in the U.S. at the time the survey was taken were considered ( $\left.n=309\right)$.

breeding programs in Arkansas and Virginia (Carneiro et al., 2021).

In addition to the positive impression of domestic vegetables, participants expressed a positive impression of certified organic vegetables produced following USDA organic standards (mean $=4.2 \pm 1.3$ ), and a slightly positive impression of nonGMO vegetables, which are vegetables without any genetic modification/ bioengineering (mean $=3.9 \pm 1.5$ ). Although the statement was about vegetables in general, not only edamame, a stronger positive attitude was also expected by the researchers toward non-GMO. It is important to consider one limitation of our study that may have impacted the answer to this question was the use of a 6-point Likert scale, which did not offer a neutral choice to the respondents and forced them to choose between "somewhat disagree" (3) and "somewhat agree" (4). Additionally, our respondents slightly agreed they would pay more for domestically produced edamame (mean $=3.7 \pm 1.2$ ), but somewhat disagreed they would pay more for certified organic edamame (mean $=3.3 \pm 1.5$ ) or certified non-GMO edamame $($ mean $=3.0 \pm 1.5)$. This result differs from a recent economics study conducted in Arkansas that reported significantly higher willingness to pay for edamame labeled as non-genetically modified (Wolfe et al., 2018). Therefore, further applied economics studies are suggested to investigate consumer willingness-to-pay for the different edamame products described above (domestic vs. imported, certified organic vs. non-certified organic, GMO vs. non-GMO).

Although our survey respondents somewhat agreed that domestic edamame is available at the grocery store where they most frequently purchase vegetables (mean $=3.6 \pm 1.5$ ), they somewhat disagreed that there is a wide range of domestically produced edamame available in the places where they do their grocery shopping (mean $=2.7 \pm 1.2$; Likert scale: $2=$ "Disagree"). This perception is in accordance with the fact the U.S. market is mostly supplied by imports and the domestic production is still low (Neill and Morgan, 2021). Although a negative impression of frozen edamame was not confirmed, our survey respondents agreed that edamame beans sold encased in their pods are better than shelled edamame beans (mean = $4.0 \pm 1.4$ ). Moreover, respondents tended to agree that frozen edamame is reasonably priced (in pod $=\$ 1.69 / 10 \mathrm{oz}$ package and shelled $=\$ 1.69 / 8 \mathrm{oz}$ package $)($ mean $=4.6 \pm 0.9)$. Thus, the prices above can serve as references for future economic studies and for growers and producers who aim to sell their edamame products directly to consumers.

\section{Edamame Purchase Intent}

Edamame is a vegetable with high nutritional value and a vegetarian/vegan-friendly source of protein (Carneiro et al., 2020). In fact, Kelley and Sánchez (2005) reported that most participants of their consumer studies expressed a positive likelihood to purchase edamame after they were informed about its health benefits. According to Nardi et al. (2019), consumers have a stronger tendency to turn their intention into consumption when the food choice regards healthy or hedonic products. Our participants ranked the four most important factors and product characteristics in their decision-making process to buy edamame and results are shown in Table 4. Price was the most important factor for the participants, and it was followed by availability and familiarity with the vegetable brand. Price was also identified by Montri et al. (2006) as one of the main factors that affect edamame consumers' decision to buy a new produce from supermarkets in the early 2000 s; it had similar average score to "sample of the produce at supermarket," but it was rated below "friend's recommendation." Drugău-Constantin (2019) also reported "recommendation from a friend/family/known acquaintance" as the major factor that influences U.S. consumers' purchase decision. Although "friend's recommendation" was not a factor that we directly investigated in our study, our participants showed disagreement (mean = $2.9 \pm 1.3$; Likert scale: $2=$ "Disagree" and $3=$ "Somewhat disagree") with the statement "my choice of buying domestically 
TABLE 5 | Correlation between edamame purchase factors or product characteristics ranked by consumers in the U.S.

\begin{tabular}{|c|c|c|c|c|}
\hline Factor or product characteristic & By factor or product characteristic & Count (Pairs) & Spearman $\rho$ & $\operatorname{Prob}>|\rho|^{a}$ \\
\hline F2 = Familiarity with the vegetable brand & $\mathrm{F} 1=$ Price & 125 & -0.0545 & 0.5464 \\
\hline \multirow[t]{2}{*}{ F3 = Availability } & $\mathrm{F} 1=$ Price & 219 & -0.3456 & $<0.0001$ \\
\hline & F2 = Familiarity with the vegetable brand & 119 & -0.2218 & 0.0153 \\
\hline \multirow[t]{3}{*}{ F4 = Certified organic } & $\mathrm{F} 1=$ Price & 70 & -0.3951 & 0.0007 \\
\hline & F2 = Familiarity with the vegetable brand & 31 & -0.3148 & 0.0846 \\
\hline & $\mathrm{F} 3=$ Availability & 62 & -0.2963 & 0.0193 \\
\hline \multirow[t]{4}{*}{$\mathrm{F} 5=$ Non-GMO } & $\mathrm{F} 1=$ Price & 42 & -0.5763 & $<0.0001$ \\
\hline & F2 $=$ Familiarity with the vegetable brand & 18 & -0.2047 & 0.4151 \\
\hline & F3 = Availability & 29 & -0.4822 & 0.0081 \\
\hline & $\mathrm{F} 4=$ Certified organic & 31 & 0.1209 & 0.5172 \\
\hline \multirow[t]{5}{*}{ F6 $=$ Fresh (not frozen) edamame pods } & $\mathrm{F} 1=$ Price & 91 & -0.3099 & 0.0028 \\
\hline & F2 = Familiarity with the vegetable brand & 28 & -0.5038 & 0.0063 \\
\hline & $\mathrm{F} 3=$ Availability & 68 & -0.4600 & $<0.0001$ \\
\hline & $\mathrm{F} 4=$ Certified organic & 21 & -0.4488 & 0.0413 \\
\hline & $\mathrm{F} 5=$ Non-GMO & 13 & -0.0840 & 0.7850 \\
\hline \multirow{6}{*}{ F7 = Fresh (not frozen) shelled edamame beans } & $\mathrm{F} 1=$ Price & 28 & -0.4919 & 0.0078 \\
\hline & $\mathrm{F} 2=$ Familiarity with the vegetable brand & 4 & 0.5774 & 0.4226 \\
\hline & F3 = Availability & 20 & -0.1953 & 0.4092 \\
\hline & $\mathrm{F} 4=$ Certified organic & 5 & -0.2294 & 0.7105 \\
\hline & $\mathrm{F} 5=$ Non-GMO & 4 & -0.5000 & 0.5000 \\
\hline & F6 $=$ Fresh (not frozen) edamame pods & 14 & 0.3457 & 0.2260 \\
\hline \multirow[t]{7}{*}{ F8 $=$ Frozen edamame in the pods } & $\mathrm{F} 1=$ Price & 97 & -0.4236 & $<0.0001$ \\
\hline & $\mathrm{F} 2=$ Familiarity with the vegetable brand & 47 & -0.5049 & 0.0003 \\
\hline & F3 = Availability & 100 & -0.3497 & 0.0004 \\
\hline & F4 = Certified organic & 21 & -0.3977 & 0.0742 \\
\hline & $\mathrm{F} 5=$ Non-GMO & 7 & -0.3268 & 0.4744 \\
\hline & F6 $=$ Fresh (not frozen) edamame pods & 30 & 0.0381 & 0.8414 \\
\hline & F7 $=$ Fresh (not frozen) shelled edamame beans & 1 & - & - \\
\hline \multirow[t]{8}{*}{ F9 = Frozen shelled edamame beans (not in pods) } & $\mathrm{F} 1=$ Price & 50 & -0.3224 & 0.0224 \\
\hline & $\mathrm{F} 2=$ Familiarity with the vegetable brand & 24 & -0.3289 & 0.1165 \\
\hline & F3 $=$ Availability & 51 & -0.3498 & 0.0119 \\
\hline & $\mathrm{F} 4=$ Certified organic & 10 & -0.3651 & 0.2996 \\
\hline & $\mathrm{F} 5=$ Non-GMO & 6 & -0.6155 & 0.1934 \\
\hline & F6 $=$ Fresh (not frozen) edamame pods & 4 & 0.8165 & 0.1835 \\
\hline & F7 $=$ Fresh (not frozen) shelled edamame beans & 8 & -0.5429 & 0.1644 \\
\hline & F8 $=$ Frozen edamame in the pods & 14 & -0.1066 & 0.7168 \\
\hline \multirow[t]{9}{*}{ F10 = Domestically produced (not imported) } & $\mathrm{F} 1=$ Price & 90 & -0.4055 & $<0.0001$ \\
\hline & F2 $=$ Familiarity with the vegetable brand & 38 & -0.2596 & 0.1155 \\
\hline & F3 = Availability & 74 & -0.4845 & $<0.0001$ \\
\hline & $\mathrm{F} 4=$ Certified organic & 25 & -0.3690 & 0.0695 \\
\hline & $\mathrm{F} 5$ = Non-GMO & 18 & -0.3694 & 0.1314 \\
\hline & F6 $=$ Fresh (not frozen) edamame pods & 34 & 0.1544 & 0.3832 \\
\hline & F7 $=$ Fresh (not frozen) shelled edamame beans & 12 & -0.0632 & 0.8454 \\
\hline & F8 $=$ Frozen edamame in the pods & 32 & 0.0127 & 0.9448 \\
\hline & F9 = Frozen shelled edamame beans (not in pods) & 13 & -0.2842 & 0.3467 \\
\hline \multirow[t]{10}{*}{$\mathrm{F} 11=$ Imported only } & $\mathrm{F} 1=$ Price & 1 & - & - \\
\hline & F2 = Familiarity with the vegetable brand & 1 & . & - \\
\hline & F3 = Availability & 2 & -1.0000 & - \\
\hline & $\mathrm{F} 4=$ Certified organic & 0 & - & - \\
\hline & $\mathrm{F} 5=$ Non-GMO & 0 & - & - \\
\hline & F6 $=$ Fresh (not frozen) edamame pods & 0 & - & - \\
\hline & F7 $=$ Fresh (not frozen) shelled edamame beans & 0 & - & - \\
\hline & F8 $=$ Frozen edamame in the pods & 2 & -1.0000 & - \\
\hline & F9 $=$ Frozen shelled edamame beans (not in pods) & 0 & - & - \\
\hline & F10 = Domestically produced (not imported) & 0 & - & - \\
\hline
\end{tabular}

a Significant correlation is indicated by numbers in bold. 
TABLE 6 | Rank of edamame products most likely to be purchased by consumers in the U.S.

\begin{tabular}{|c|c|c|c|c|c|c|c|c|c|c|}
\hline \multirow[t]{3}{*}{ Edamame product } & \multicolumn{8}{|c|}{ Purchase intent-rank* } & \multirow[t]{3}{*}{ Total count } & \multirow[t]{3}{*}{ Product rank } \\
\hline & \multicolumn{2}{|c|}{1} & \multicolumn{2}{|c|}{2} & \multicolumn{2}{|c|}{3} & \multicolumn{2}{|c|}{4} & & \\
\hline & $\%$ & Count & $\%$ & Count & $\%$ & Count & $\%$ & Count & & \\
\hline Fresh (not frozen) edamame pods & 39.9 & 91 & 22.4 & 51 & 20.2 & 46 & 17.5 & 40 & 228 & 1 \\
\hline Frozen edamame in the pods & 37.6 & 76 & 26.7 & 54 & 19.3 & 39 & 16.3 & 33 & 202 & 2 \\
\hline Domestically produced (not imported) & 14.1 & 28 & 24.2 & 48 & 37.4 & 74 & 24.2 & 48 & 198 & 3 \\
\hline Certified organic & 24.9 & 43 & 17.3 & 30 & 30.6 & 53 & 27.2 & 47 & 173 & 4 \\
\hline Fresh (not frozen) shelled edamame beans & 11.6 & 19 & 29.3 & 48 & 28.0 & 46 & 31.1 & 51 & 164 & 5 \\
\hline Frozen shelled edamame beans (not in pods) & 25.2 & 37 & 27.9 & 41 & 20.4 & 30 & 26.5 & 39 & 147 & 6 \\
\hline Non-GMO & 13.1 & 14 & 33.6 & 36 & 16.8 & 18 & 36.4 & 39 & 107 & 7 \\
\hline Imported only & 5.9 & 1 & 5.9 & 1 & 17.6 & 3 & 70.6 & 12 & 17 & 8 \\
\hline
\end{tabular}

${ }^{*} 1$ = The most likely to buy product. Only completed surveys answered by consumers living in the U.S. at the time the survey was taken were considered ( $\left.n=309\right)$.

produced edamame (vegetable soybean) will be influenced by the opinions of my family and friends" (Table 3). Edamame in the pods was the most important product characteristic and frozen edamame products were ranked higher than similar fresh ones. Even though consumers may believe fresh fruits and vegetables are healthier or tastier, convenience is an important advantage of the frozen fruits/vegetable products that can affect consumer purchase decision (Storey and Anderson, 2018) and was possibly valued by our respondents. Convenience can be linked, for example, to easier selection, purchase, food preparation (e.g., prewashed), cooking, as well as cleaning before and/or after cooking (Storey and Anderson, 2018), and these components could be further investigated in future research. Moreover, among the 11 factors presented to rank, "domestically produced (not imported)" was ranked as the fifth most important factor, while "imported only" was ranked as the least important factor, which is consistent with the results presented in Table 3 and confirms a preference for domestic products (produced in the U.S.). A significant negative correlation was observed between 18 pairs of factors (Table 5), which means that when the rank of one factor increased, the rank of the other factor decreased. For instance, the rank of price was negatively correlated with the rank of all other factors and product characteristics $(p<0.05)$, except for "familiarity with the vegetable brand" $(p>0.05)$ and "imported only" (insufficient pairs).

Next, our participants ranked the four edamame products they were most likely to buy on the day the survey was taken. Overall, shelled edamame products ranked lower than edamame in the pods (Tables 4,6 ). The four products chosen by most consumers were: (1) fresh (not frozen) edamame in the pods, (2) frozen edamame in the pods, (3) domestically produced (not imported), and (4) certified organic (Table 6). Even though consumers perceived a low availability of domestically produced edamame where they do their grocery shopping (Table 3, question 22), "imported only" was the least chosen purchase option, which reinforces previous suggestion that domestic edamame products (not imported) are valued by consumers in the U.S. (Table 6). Furthermore, our purchase intention results are aligned with the consumer study performed by Montri et al. (2006) in the metropolitan Philadelphia area. Authors reported that consumers would prefer to buy fresh edamame in-shell (in the pods) only $(48.5 \%)$ or both shelled and in the pods (48.5\%), instead of shelled (beans) only (3\%). Also, most participants in their study reported they were more likely to buy edamame because it was produced in Pennsylvania. Shelled beans may not be the consumer most preferred option for edamame products, but they may be valuable for food service menus (e.g., salad bars). Consumer attitude toward food service retail selection options preferences was not investigated in our survey and future study can help identify alternative routes of sales for the different edamame products. As shown in Table 3, our participants slightly agreed that they would pay more for domestically produced edamame relative to nondomestically produced edamame (mean $=3.7 \pm 1.2$; Likert scale: 3 = "Somewhat disagree" and $4=$ "Somewhat agree"). Thus, future studies are important to quantify how much consumers are willing to pay for different types of domestic edamame. For instance, Wolfe et al. (2018) reported consumers in the U.S. are willing to pay more (at least $\$ 0.42$ more) for non-GMO labeled edamame in comparison with unlabeled or GMO labeled edamame. However, in our study, non-GMO edamame was ranked as the seventh edamame product most likely to be purchased by our participants from our list of 8 products (Table 6) and ranked nineth from our list of 11 factors considered during the purchase decision process. It suggests that when analyzed within a broader set of factors (not directly related), consumers may value other factors, such as convenience, over production characteristics, such as nonGMO, for example. A significant negative correlation was observed between 17 pairs of edamame products (Table 7). The rank of domestically produced (not imported) edamame was negatively correlated with the rank of all other factors and product characteristics $(p<0.05)$, except for "frozen shelled edamame beans (not in pods)" and "imported only" $(p>0.05)$. However, as "important only" was not chosen by many respondents, the low number of pairs possibly affected statistical analysis. 
TABLE 7 | Correlation between edamame products ranked by consumers in the U.S.

\begin{tabular}{|c|c|c|c|c|}
\hline Variable & By variable & Count (Pairs) & Spearman $\rho$ & $\operatorname{Prob}>|\rho|^{a}$ \\
\hline P2 = Non-GMO & $\mathrm{P} 1=$ Certified organic & 87 & 0.1837 & 0.0885 \\
\hline \multirow[t]{2}{*}{ P3 = Fresh (not frozen) edamame pods } & $\mathrm{P} 1=$ Certified organic & 107 & -0.4170 & $<0.0001$ \\
\hline & $\mathrm{P} 2=$ Non-GMO & 57 & -0.3976 & 0.0022 \\
\hline \multirow[t]{2}{*}{ P4 = Fresh (not frozen) shelled edamame beans } & $\mathrm{P} 1=$ Certified organic & 66 & -0.5466 & $<0.0001$ \\
\hline & $\mathrm{P} 2=$ Non-GMO & 31 & -0.4277 & 0.0164 \\
\hline & $\mathrm{P} 2=$ Non-GMO & 51 & -0.5164 & 0.0001 \\
\hline & P3 $=$ Fresh (not frozen) edamame pods & 153 & -0.3423 & $<0.0001$ \\
\hline & P4 = Fresh (not frozen) shelled edamame beans & 86 & -0.5249 & $<0.0001$ \\
\hline \multirow[t]{2}{*}{ P6 = Frozen shelled edamame beans (not in pods) } & $\mathrm{P} 1=$ Certified organic & 51 & -0.2673 & 0.0579 \\
\hline & $\mathrm{P} 2=$ Non-GMO & 28 & -0.6971 & $<0.0001$ \\
\hline \multirow[t]{6}{*}{ P7 = Domestically produced (not imported) } & $\mathrm{P} 1=$ Certified organic & 113 & -0.3013 & 0.0012 \\
\hline & $\mathrm{P} 2=$ Non-GMO & 66 & -0.4608 & $<0.0001$ \\
\hline & P3 = Fresh (not frozen) edamame pods & 133 & -0.3311 & $<0.0001$ \\
\hline & P4 = Fresh (not frozen) shelled edamame beans & 84 & -0.3447 & 0.0013 \\
\hline & P5 $=$ Frozen edamame in the pods & 117 & -0.2113 & 0.0222 \\
\hline & P6 $=$ Frozen shelled edamame beans (not in pods) & 67 & -0.1879 & 0.1278 \\
\hline \multirow[t]{5}{*}{ P8 = Imported only } & $\mathrm{P} 1=$ Certified organic & 5 & -0.5526 & 0.3340 \\
\hline & $\mathrm{P} 2=$ Non-GMO & 1 & - & - \\
\hline & P3 = Fresh (not frozen) edamame pods & 11 & - & - \\
\hline & P4 = Fresh (not frozen) shelled edamame beans & 3 & -1.0000 & $<0.0001$ \\
\hline & P5 $=$ Frozen edamame in the pods & 13 & 0.0000 & 1.0000 \\
\hline
\end{tabular}

${ }^{a}$ Significant correlation is indicated by numbers in bold.

\section{CONCLUSION}

Our study suggested there is a positive attitude toward domestically produced edamame in the U.S. market, as hypothesized, and identified a higher purchase intention for domestic edamame products. A higher preference and purchase intention were also identified for in-shell edamame products. Edamame is a specialty crop not yet largely produced in the U.S. and our findings provide valuable insights to support future studies that can help promote a sustainable growth of the edamame agrobusiness in the country. As price was identified as the major factor in the consumer decisionmaking process to buy edamame in the U.S., future economic studies that investigate willingness-to-pay for a diverse set of domestic edamame products (e.g., frozen vs. fresh, in-shell vs. shelled, certified organic vs. non-certified organic, nonGMO vs. GMO) can help local growers and processors develop their business strategies. Likewise, the market potential for organic production of edamame needs to be further investigated. The fact that consumers value a consistent sensory quality of edamame products reinforces the need for developing improved cultivars and standardizing production practices with the support of sensory data. Additionally, exploration of other value-added processed products with edamame as a major ingredient could possibly expand the interest in and motivation for edamame and further investigation is recommended. As a positive relationship between edamame consumption and gender identity was suggested, it would be valuable to further explore the impact of self-identity (e.g., self-reported gender, age, or ethnic/racial background) in the TPB variables as well as in the future consumption of edamame products in the U.S. (food choice behavior). Moreover, as a possible alternative to enrich the TPB model and complement our findings, complementary constructs such as risk perception, trust, and past behaviors could also be further explored in the context of investigating consumption of domestic edamame.

\section{DATA AVAILABILITY STATEMENT}

The raw data supporting the conclusions of this article will be made available by the authors, without undue reservation. 


\section{ETHICS STATEMENT}

The studies involving human participants were reviewed and approved by Virginia Tech Institutional Review Board (IRB) for research involving human subjects (IRB 20-023). The patients/participants provided their written informed consent to participate in this study.

\section{AUTHOR CONTRIBUTIONS}

$\mathrm{RC}, \mathrm{TD}, \mathrm{CN}$, and SD contributed with conception of the study and questionnaire design. RC collected and analyzed consumer

\section{REFERENCES}

Ajzen, I. (1991). The theory of planned behavior. Org. Behav. Hum. Dec. Proc. 50, 179-211. doi: 10.1016/0749-5978(91)90020-T

Barjolle, D., Gorton, M., Đorðević, J. M., and Stojanović, Ž. (2013). Food Consumer Science. Berlin: Springer.

Carfora, V., Caso, D., and Conner, M. (2015). The role of self-identity in predicting fruit and vegetable intake. Appetite 106, 23-29. doi: 10.1016/j.appet.2015.12.020

Carneiro, R., Duncan, S., O’Keefe, S., Yu, D., Huang, H., Yin, Y., et al. (2021). Utilizing consumer perception of edamame to guide new variety development. Front. Sustain. Food Syst. 4:556580. doi: 10.3389/fsufs.2020.556580

Carneiro, R. C. V., Duncan, S. E., O'Keefe, S. F., Yin, Y., Neill, C. L., and Zhang, B. (2020). Sensory and consumer studies in plant breeding: a guidance for edamame development in the U.S. Front. Sustain. Food Syst. 4:124. doi: $10.3389 /$ fsufs.2020.00124

Carson, L., Freeman, J., Zhou, K., Welbaum, G., and Reiter, M. (2011). Cultivar evaluation and lipid and protein contents of Virginia-grown edamame. Horttechnology 1, 131-135. doi: 10.21273/HORTTECH.21.1.131

Drugău-Constantin, A. (2019). Is consumer cognition reducible to neurophysiological functioning? Econom. Manag. Finan.l Mark. 14, 9-14. doi: 10.22381/EMFM14120191

Emanuel, A. S., Mccully, N., Gallagher, K. M., and Updegraff, J. A. (2012). Theory of Planned Behavior explains gender difference in fruit and vegetable consumption. Appetite 59, 693-697. doi: 10.1016/j.appet.2012.08.007

Flores, D., Giovanni, M., Kirk, L., and Liles, G. (2019). Capturing and explaining sensory differences among organically grown vegetablesoybean varieties grown in Northern California. J. Food Sci. 84, 613-22. doi: 10.1111/1750-3841.14443

Gliem, J. A., and Gliem, R. R. (2003). "Calculating, interpreting, and reporting Cronbach's alpha reliability coefficient for Likert-type scales," in: Midwest Research to Practice Conference in Adult, Continuing, and Community Education, 82-88. Available online at: https://scholarworks.iupui. edu/bitstream/handle/1805/344/gliem $+\&+$ gliem.pdf?sequence $=1$

Kelley, K. M., and Sánchez, E. S. (2005). Accessing and understanding consumer awareness of and potential demand for edamame. HortScience 40, 1347-1353. doi: 10.21273/HORTSCI.40.5.1347

Mebrahtu, T., and Devine, T. E. (2008). Combining ability analysis for selected green pod yield components of vegetable soybean genotypes (Glycine max). N Zeal. J. Crop Horticult. Sci. 36, 97-105. doi: 10.1080/01140670809510225

Montri, D. N., Kelley, K. M., and Sánchez, E. S. (2006). Consumer interest in fresh, in-shell edamame and acceptance of edamame-based patties. HortScience 41, 1616-1622. doi: 10.21273/HORTSCI.41.7.1616

Nardi, V. A. M., Jardim, W. C., Ladeira, W., and Santini, F. (2019). Predicting food choice: a meta-analysis based on the theory of planned behavior. Br. Food J. 121, 2250-2264. doi: 10.1108/BFJ-08-2018-0504

Neill, C. L., and Morgan, K. L. (2021). Beyond scale and scope: exploring economic drivers of u.s. specialty crop production with an application to edamame. Front. Sustain. Food Syst. 4:582834. doi: 10.3389/fsufs.2020.582834 data, wrote first draft, and edited manuscript. Manuscript was reviewed and approved by all authors.

\section{FUNDING}

This work was funded by USDA-NIFA (Grant No. 2018-5118128384; Accession No. 1016465), and, in part, by the Virginia Agricultural Experiment Station.

\section{ACKNOWLEDGMENTS}

The authors thank all the volunteers who participated in this study.

Nolen, S., Zhang, B., and Kering, M. K. (2016). Increasing fresh edamame bean supply through season extension techniques. J. Horticult. 3, 1-5. doi: 10.4172/2376-0354.1000170

Ogles, C. Z., Guertal, E. A., and Weaver, D. B. (2016). Edamame cultivar evaluation in Central Alabama. Agron. J. 108, 2371-2378. doi: 10.2134/agronj2016.04.0218

Pocol, C. B., Marinescu, V., Dabija, D.-C., and Amuza, A. (2021). Clustering Generation $\mathrm{Z}$ university students based on daily fruit and vegetable consumption: empirical research in an emerging market. Br. Food J. 123, 2705-2727. doi: 10.1108/BFJ-10-2020-0900

Steptoe, A., Pollard, T. M., and Wardle, J. (1995). Development of a measure of the motives underlying the selection of food: the food choice questionnaire. Appetite 25, 267-284. doi: 10.1006/appe.199 5.0061

Storey, M., and Anderson, P. (2018). Total fruit and vegetable consumption increases among consumers of frozen fruit and vegetables. Nutrition 46, 115 121. doi: 10.1016/j.nut.2017.08.013

Vabø, M., and Hansen, H. (2016). Purchase intentions for domestic food: a moderated TPB-explanation. Br. Food J. 118, 2372-2387. doi: 10.1108/BFJ-01-2016-0044

Wolfe, E., Popp, M., Bazzani, C., Nayga, R. M., Danforth, D., Popp, J., et al. (2018). Consumers' willingness to pay for edamame with a genetically modified label. Agribusiness 34, 283-299. doi: 10.1002/agr. 21505

Zhang, L., and Kyei-Boahen, S. (2007). Growth and yield of vegetable soybean (edamame) in Mississippi. HortTechnology 17, 26-31. doi: 10.21273/HORTTECH.17.1.26

Zhang, Q., Li, Y., Chin, K. L., and Qi, Y. (2017). Vegetable soybean: Seed composition and production research. Italian J. Agron. 12, 276-282. doi: $10.4081 /$ ija.2017.872

Conflict of Interest: The authors declare that the research was conducted in the absence of any commercial or financial relationships that could be construed as a potential conflict of interest.

Publisher's Note: All claims expressed in this article are solely those of the authors and do not necessarily represent those of their affiliated organizations, or those of the publisher, the editors and the reviewers. Any product that may be evaluated in this article, or claim that may be made by its manufacturer, is not guaranteed or endorsed by the publisher.

Copyright (C) 2022 Carneiro, Drape, Neill, Zhang, O'Keefe and Duncan. This is an open-access article distributed under the terms of the Creative Commons Attribution License (CC BY). The use, distribution or reproduction in other forums is permitted, provided the original author(s) and the copyright owner(s) are credited and that the original publication in this journal is cited, in accordance with accepted academic practice. No use, distribution or reproduction is permitted which does not comply with these terms. 